\title{
Pulmonary hypertension in valve disease: A beast of the past?
}

\author{
Manuel J. Antunes, MD, PhD, DSc
}

\footnotetext{
From the Department of Cardiothoracic Surgery, Faculty of Medicine and University Hospital, Coimbra, Portugal.

Disclosures: Author has nothing to disclose with regard to commercial support.

Received for publication Jan 10, 2016; accepted for publication Jan 15, 2016; available ahead of print Feb 12, 2016.

Address for reprints: Manuel J. Antunes, MD, PhD, DSc, Centro de Cirurgia Cardiotorácica, Centro Hospitalar Universitário de Coimbra, Praceta Professor Mota-Pinto, 3000-075 Coimbra, Portugal (E-mail: antunes.cct. chuc@sapo.pt).

J Thorac Cardiovasc Surg 2016;151:1300-1

$0022-5223 / \$ 36.00$

Copyright $(2016$ by The American Association for Thoracic Surgery

http://dx.doi.org/10.1016/j.jtcvs.2016.01.026
}

In an article published in this issue of the Journal, Enter and colleagues ${ }^{1}$ from McCarthy's group from the Northwestern University analyze the impact of preoperative pulmonary hypertension (PHTN) in the early and late outcomes of mitral valve operations in 1571 patients operated on from 2004 to 2013, stratified according to their systolic pulmonary arterial pressure (SPAP) measured by either echocardiography or right-heart catheterization. They also analyzed the influence of concomitant tricuspid valve surgery in the outcomes. Patients with severe PHTN (SPAP of 50$79 \mathrm{~mm} \mathrm{Hg}$ ) had higher 30-day and late mortalities than patients with no hypertension; however, this negative impact was not confirmed in the propensity score-matched pairs. Extreme PHTN (SPAP of $\geq 80 \mathrm{~mm} \mathrm{Hg}$ ), however, remained a risk factor. Addition of tricuspid valve surgery did not affect early or late survival.

Severe PHTN was identified as a risk factor in virtually all series published previously, but the separation between severe and extreme hypertension was usually not made. In a recently published work, my own group found that late survival, to as late as 22 years of follow-up, was impaired in 382 symptom-free patients with preserved left ventricular function and systolic dimension submitted to elective surgery for severe degenerative mitral regurgitation who had preoperative SPAP from 50 to $59 \mathrm{~mm} \mathrm{Hg}$ or at least $60 \mathrm{~mm} \mathrm{Hg}$ (Figure 1). ${ }^{2}$ In fact, SPAP greater than $30 \mathrm{~mm}$ $\mathrm{Hg}$ is included as a risk factor in the recently introduced and now widely used euroSCORE II.

Thus if statistics are correct (and this was confirmed by the Journal's statistical editor), this study by Enter and colleagues ${ }^{1}$ may bring new knowledge. I still remember, in the beginning of my career some 40 years ago, that association of tight mitral valve stenosis and pulmonary arterial pressure close to or even above systemic was seen as a very ominous prognostic factor, and some patients were denied surgery for that reason. Currently, the vast majority of surgeons would not think of severe PHTN as a contraindication to mitral valve surgery, but it is comforting to know that it is not a risk factor either.

Naturally, the presence of moderate and severe PHTN requires extra intraoperative and perioperative care, although

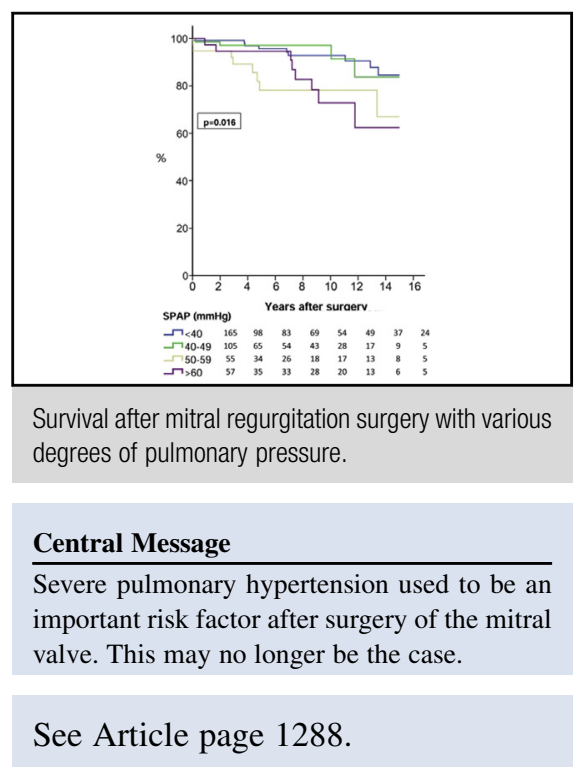

Enter and colleagues ${ }^{1}$ did not touch this subject in their report. Obviously, we have learned to deal with PHTN, especially with lesser degrees of hypertension. Better knowledge of the mechanisms and new inotropic and pulmonary vasodilator drugs have helped immensely. ${ }^{4}$

One possible drawback of the article of Enter and colleagues ${ }^{1}$ is that information about the late vital status was based at least in part on data from the Social Security Death Index. Apparently, after a 2011 Social Security Death Index purge, $39 \%$ of death records have been eliminated. It is difficult to determine the impact this may have had on the study of Enter and colleagues. ${ }^{1}$ Confronted with this during the revision process, the authors responded that their "inclusive and multilayered approach to vital status assessment produces the most current information that one could hope to be able to gather ... at the present time." In addition, a maximum follow-up of just more than 10 years may be a limitation in this series, because there may be a tendency toward a late increase in mortality.

In contrast, almost everybody now believes that concomitant tricuspid valve surgery adds little if any surgical risk, and it may provide benefit in the long term. Many studies have demonstrated improved long-term survival after tricuspid valve repair during mitral valve surgery. Consequently, current guidelines from both sides of the Atlantic give repair of severe tricuspid valve regurgitation (TR) in patients undergoing left-sided valve surgery a class I recommendation, and the trend is to extend it to lesser degrees of regurgitation. ${ }^{5,6}$

PHTN may coexist with no or severe TR, although the association of severe PHTN and severe TR is rare. The 


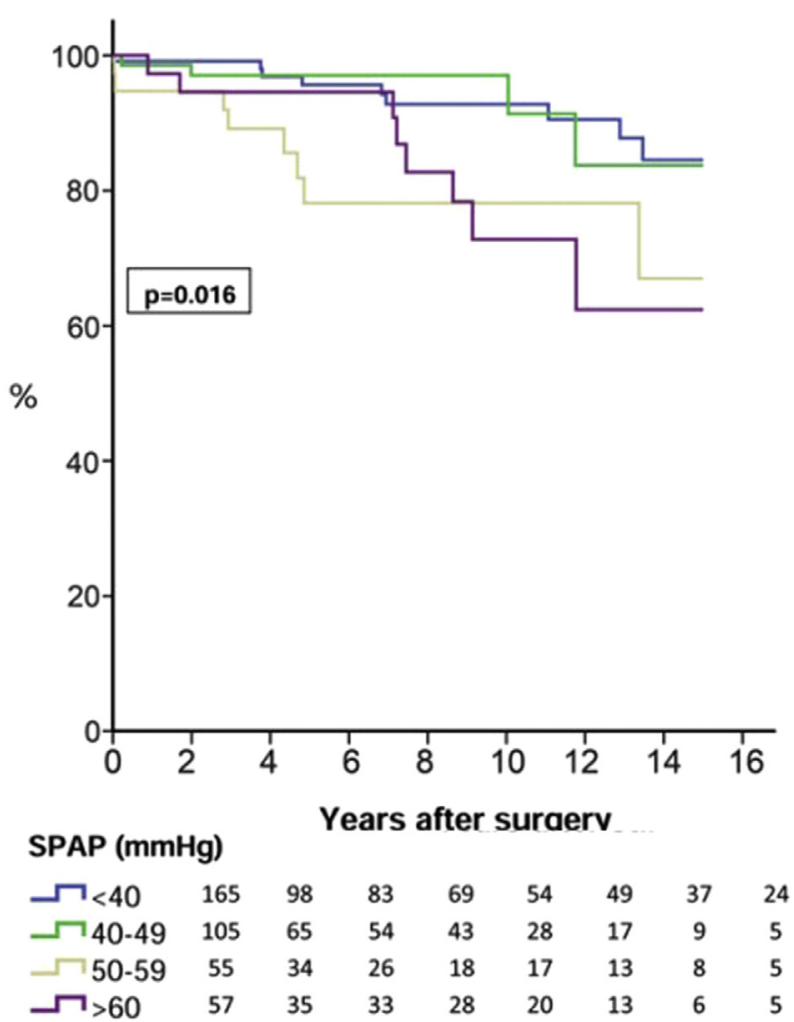

FIGURE 1. Overall survival curves in a series of 382 symptom-free patients submitted to elective surgery for severe degenerative mitral regurgitation with different degrees of preoperative systolic pulmonary artery pressure $(S P A P)$. (Adapted with permission. ${ }^{2}$ )

relationship between SPAP and TR remains unclear, however, and the individual impacts of these 2 factors on early and late outcomes is largely unknown. In their work, Enter and colleagues ${ }^{1}$ did not find a negative impact of adding repair of TR to mitral valve surgery in patients with PHTN; however, an increased need for permanent pacemaker implantation was observed among patients undergoing tricuspid valve repair in both the original and the propensity score-matched groups. Although permanent pacemaker implantation is currently not considered a serious complication, it does have some important long-term implications, such as lead and generator pocket infection, the negative impact of which ought not to be overlooked.

Finally, there is another factor in this equation that was completely ignored in the article by Enter and colleagues, ${ }^{1}$ the right ventricle (RV). Both PHTN and TR associated with left heart valve disease have a relationship with the size and function of the RV. ${ }^{7,8}$ Significant RV dysfunction is unequivocally associated with poor long-term prognosis, even after successful tricuspid valve repair. Interestingly, preoperative TR arose as an independent risk factor for late mortality my own groups' cited work. ${ }^{2}$ That is one good reason for repairing TR early, before it has a negative influence on the RV. RV dysfunction, perhaps with the exception of extreme cases, should not be considered a contraindication to surgery on the mitral and tricuspid valves; again, however, perioperative and postoperative management should be especially adapted to the circumstances.

In conclusion, the work of Enter and colleagues ${ }^{1}$ is generally not in accordance with most articles previous published on this subject. It thus may constitute new knowledge, but we will have to wait for confirmation of these results by other investigators.

\section{References}

1. Enter DH, Zaki A, Duncan BF, Kruse J, Andrei AC, Li Z, et al. A contemporary analysis of pulmonary hypertension in patients undergoing mitral valve surgery: is this a risk factor? J Thorac Cardiovasc Surg. 2016;151:1288-99.

2. Coutinho GF, Garcia AL, Correia PM, Branco C, Antunes MJ. Negative impact of atrial fibrillation and pulmonary hypertension after mitral valve surgery in asymptomatic patients with severe mitral regurgitation: a 20-year follow-up. Eur J Cardiothorac Surg. 2015;48:548-55; discussion 555-6.

3. Nashef SA, Roques F, Sharples LD, Nilsson J, Smith C, Goldstone AR, et al. EuroSCORE II. Eur J Cardiothorac Surg. 2012;41:734-44; discussion 744-5.

4. Adir Y, Amir O. Pulmonary hypertension associated with left heart disease. Semin Respir Crit Care Med. 2013;34:665-80.

5. Vahanian A, Alfieri O, Andreotti F, Antunes MJ, Barón-Esquivias G, Baumgartner $\mathrm{H}$, et al; ESC Committee for Practice Guidelines (CPG); Joint Task Force on the Management of Valvular Heart Disease of the European Society of Cardiology (ESC); European Association for Cardio-Thoracic Surgery (EACTS). Guidelines on the management of valvular heart disease (version 2012): the Joint Task Force on the Management of Valvular Heart Disease of the European Society of Cardiology (ESC) and the European Association for Cardio-Thoracic Surgery (EACTS). Eur J Cardiothorac Surg. 2012; 42:S1-44.

6. Nishimura RA, Otto CM, Bonow RO, Carabello BA, Erwin JP III, Guyton RA, et al; ACC/AHA Task Force Members. 2014 AHA/ACC guideline for the management of patients with valvular heart disease: executive summary: a report of the American College of Cardiology/American Heart Association Task Force on Practice Guidelines. Circulation. 2014;129:2440-92. Erratum in: Circulation. 2014;129:e650.

7. Antunes MJ, Barlow JB. Management of tricuspid valve regurgitation. Heart 2007:93:271-6.

8. Bogaard JH, Abe K, Vonk Noordegraaf A, Voelkel NF. The right ventricle under pressure: cellular and molecular mechanisms of right-heart failure in pulmonary hypertension. Chest. 2009;135:794-804. 